cious upper deck, where they run about and get the full benefit of the salt breezes. The trained nurse in charge of this deck has a watchful eye over all, and circulates among the mothers, giving many useful health hints and suggestions as to the proper care of their little ones. To many of the women she says, "I think baby would be better for a nice salt water bath," and the mother and child go below to the bath-rooms. There are five tubs, five spray baths for children, and two spray baths for women, with another trained nurse in charge of them, and many baths are given during every trip. The worst cases are carefully put to bed in two large, airy rooms on the lower deck, and the most of these are left at the seaside hospital of the Guild, where they remain for ten days or so. Besides the physicians and nurses, the working force of the floating hospital consists of a captain, pilot, six deck hands, watchman, engineer, two cooks, and ten waitresses. Two lifeboats are towed behind, in each of which sits a sailor, on the outlook for any child which may fall overboard.

After an invigorating sail down the beautiful bay and through the Narrows, the boat comes to anchor half a mile from the Seaside Hospital on Staten Island, and the patients destined for this institution are rowed ashore. Those remaining on the barge are then taken downstairs and given a bountiful dinner. The milk used for the children is the purest that can be obtained, and it is carefully sterilized and tested before it is put on board. The Seaside Hospital, which is beautifully situated almost at the water's edge, can accommodate over 250 patients, and the arrangement of the beds in its cool and lofty wards is quite novel. From the foot of the iron bedsteads used by the mothers rise two iron supports which curve above the bed like the davits on a ship, and from these a crib is suspended at right angles to the bed. The sick child thus hangs in the air immediately above its mother, and she can attend to its wants instantly, and without rising from her own bed. There are ten acres of land about the hospital, with a fine cedar grove, and with the most abundant facilities for sea bathing. Other institutions which prove of inestimable benefit to the children of the poor are the Summer Home of the Children's Aid Society, the St. George Sanitarium, and the Summer Branch of St. Mary's Free Hospital for Children, all of which are located on the Long Island sea coast.

P. B. $P$.

\section{KANSAS CITY LETTER.}

Vaginal Hysterectomy for Carcinoma-Insanity Following Rectal Operation-Methyl-violet for Cancerous Growths-A New College Organized-College Notes.

The meetings of the Academy of Medicine have of late been unusually interesting. At the last, Dr. J. F. Binnie, Professor of Pathology in the University, discussed the subject of

VAGINAL, HYSTERECTOMY FOR CARCINOMA.

He first presented the history of a case successfully operated upon by himself seven months ago, exhibiting the specimen as well as slides showing the cancerous character of the disease, and then gave a table of $I, I 69$ cases gathered from published reports and from private communication of hitherto unpublished operations; these figures gave a mortality of less than twelve per centum, the total number of deaths being only 137 -in view of which it takes a bold man to say the operation is unjustifiable because of immediate danger. And the ultimate results are no less satisfactory-in fact they are rather surprising inasmuch as a careful study of cases operated upon years ago shows that more than 50 per cent. of all cases operated upon permanently recover. This is a somewhat remarkable showing, but it bears out Schauta's estimate of 47 per cent. permanent recovery and places the operation of vaginal hysterectomy far in advance of many procedures generally accepted is justifiable; for example, amputation of the breast for malignant disease, König's statistics giving only 23 per cent. of recoveries in the latter operation. After a thorough analysis of the subject Dr. Binnie formulated these conclusions:

I. Vaginal hysterectomy is a comparatively safe operation.

2. In many cases vaginal hysterectomy effects an absolute cure. Where it does not do so it generally gives relief from distressing symptoms.

3. The more localized the carcinoma, the sooner should total extirpation be done.

4. When it is surmised, but not positively known, that all the disease cannot be removed, the operation ought to be performed.

5. Adhesions in the upper part of the uterus, when there is cancer in the lower, call for at least, an exploratory laparotomy, and if the adhesions prove to be the result of inflammation, hysterectomy may be made.

6. Superficial extension of the disease over the vagina does not absolutely contra-indicate the operation.

7. Clamps, for the control of hæmorrhage, are probably as safe as ligatures, if antiseptic precautions are vigorously attended to; certainly their application is infinite$1 y$ easier and more rapid.

Dr. George Halley, in discussing the paper, said he had made the operation in eight cases with but two deaths as the immediate result, and though there has been a return of the disease in two cases the recurrence has been in the mesentary and liver, and life has not been so miserable as it would have been with the terrible pains and offensive discharge of primary uterine carcinoma; besides, life has undeniably been prolonged from one to four years. In two of these cases there has been a radical cure; a number of years have elapsed and there has been absolutely no evidence of return; yet careful microscopic examination shows the disease to have been unquestionably cancerous in both cases. Involvement of the vaginal wall does not necessarily contra-indicate operation as in one case the vagina was extensively infiltrated and death would undoubtedly have occurred in a few months, but careful dissection of all affected tissues and vaginal extirpation prolonged the life of the patient almost three years; she died with but little suffering-always thankful for the temporary relief from horrible distress.

INSANITY AFTER RECTAL OPERATION.

Dr. Emory Lanphear lately reported to the Academy 
the case of a womat, aged 40, suffering from pyosalpinx, and had hæmorthoids with fissure; her general condition was bad-the patient nervous and emaciated, and troubled with obstinate constipation and some insomuia. She was put in the hospital for some weeks and improved greatly, the appetite becoming good, sleep excellent, bowels reguiar and loose, and the strength quite satis. factory - so an operation on the rectum was deemed ad. visable. Under chloroform, Dr. Lanphear removed the entire lower part of the rectum, with some hard, infilitrated connective tissue surrounding it, pulting healthy mucous nembrane down to cover the denuded surface; iodoform was applied freely and the bowel packed with iodoform gauze, bichloride gauze and cotton over outside. She was put to bed without shock and with no subsequent bad symptom, such as pain, rise of temperature etc. The wound healed by first intention everywhere except at one point where there was pus formation.

On the fifteenth day there was still some pus discharging, and considerable pain at stool, but patient had been gaining at least a pound daily in weight, the temperature was normal, bowels regular, and sleep satisfactory without hypnotics. The next day she became despondent, crying much; the next there was considerable incoherency with the melancholia, but under twenty grains of bromide of sodium she slept nine hours. The next morning she was a perfect picture of dementia; the next she was somewhat excited but passed into a stupid condition soon. The next morning she was apparently unconscious, pulse 60 , respiration 16 , and temperature normal; she swallowed food (milk and milk punch) and medicine nicely during the day. In the evening she was seen by Prof. J. M. Allen, also; he gave an unfavorable prognosis as he had some years ago a case of insanity following operation for fistula in which there was a fatal termination, with no discoverable cause. The next day witnessed no improvement; she began menstruating in the afternoon, and exhibited some evidence of pain and ovarian tenderness under pressure; temperature $991 / 2^{\circ} \mathrm{F}$. On the next day the temperature began to rise, the respiration ran up to 56 per minute and marked emaciation became manifest. The record for the next morning was: temperature $103 \%^{\circ}{ }^{\circ} \mathrm{F}$., pulse 140 and respiration 144 per minute! Of the accuracy of this observation, Dr. Lan. phear said there would be no doubt as it was repeatedly verified during the next 30 hours, the patient dying at 2 P. M., of the following day. No autopsy was obtainable.

The probabilities are that the mental disturbance and subsequent cause were due to septic poisoning, but if so the manifestations of septicæmia were of a very peculiar character to say the least. One theory advanced was that the nerve-centers gave way simply from the reflex irritation coupled with the effect of the anæsthetic; in two cases of removal of the uterine appendages reported here some two or three years ago, insanity followed with in a few days after operation-and one case has become hopelessly demented. Whether the case here mentioned would have proven an instance of post-operative insanity if the woman had lived is a question for speculation. ANILINE DYES FOR CANCER.

Methyl-violet, after the method advocated by Moosetig von Moorhof, is being extensively tried in this city for the cure of inoperable malignant growths. One case under the care of Dr. J. W. Perkins of St. Margaret's hospital showed some improvement and marked immunity from pain after each injection; the growth-sarcomawas most painful, necessitating the hypodermic use of a half grain of morphine every four hours, but the patient was able to go from sixteen to twenty-four hours with no morphine whenever the pyoktanin injections were made.

Other cases under Drs. Fulton, Block, Griffith, Binuie and others at St. Joseph's, All Saints', the German and City Hospitals have shown wonderful results. At the Academy, Dr. J. D. Griffith, Professor of Surgery in the K. C. Medical College, recently reported seven cases in which he had used the drug. Of the seven cases one died, two were (apparently) completely cured-patients exhibited to the Academy-and all the others are improving. Two cases were epithelioma of the face, one epithelioma of the cervix, one osteo-sarcoma of the upper and lower jaw, one adeno-sarcoma of the side of neck and face, the other two sarcomatous tumors, inoperable. One of the cases presented adeno-sarcoma is 27 years of age, came under treatment some weeks ago, for a very large tumor of the right side of the face and neck; it was of a slow and painful growth, and presented all the symptoms of malignant growths of glands, and examination showed it to be a true adeno-sarcoma, involving the parotid and submaxillary glands. Treatment was begun by injecting twenty minums before and behind, the solution being I to 500, carefully sterilized, the face being thoroughly cleansed by antiseptic solutions to prevent the introduction of any material which might cause suppuration. The injections were repeated every other day and rapidly increased in quantity. In two weeks the tissues began to break down; the fluid contents were carefully aspirated and the injections continued, care being taken to throw the solution into the tissues around and not into the cavity in the growth. The tumor rapidly diminished in size as the injections were repeated and the quantity of fiuid increased; at last three drachms of the solution were used every second day. There never was any pus present, the fluid withdrawn consisting simply of serum, broken down connective tissue, a few leucocytes and many cancer cells; the most careful examination failed to show any staphylococci or streptococci of suppuration. Soon the tumor shrank to almost nothing and now presents no trace of the malignant disease that promised to end his life in a short time.

The other case shown [osteo-sarcoma affecting the molar, superior maxillary and inferior maxillary] was treated in the same way, but with more difficulty, owing to the extreme hardness of the tissues; as only a few drops could be deposited in one place, many punctures had to be made and never could more than sixty minims be injected at one sitting; yet cure is seemingly complete.

In the fatal case, operation had been made some months ago for small epithelioma of the lip. An immense secondary growth sprang up, which, when patient was admitted to the hospital, hung down upon his breast; the parotid gland upon the left side was implicated as were all the glands along the sterno-cleido-mas. toid. Upon the lower end of this enormous tumor there was a large ulcer to which some quack had been apply. ing fresh frogs' skins (!) allowing them to remain until thestench would become intolerable. 'The man was suffering intensely, could not sleep, or eat, and had marked symptoms of septicemia. But treatment was instituted by the usual injections, only in larger quantities- -160 minims being finally used-and painting the ulcer with 
the pure stick methyl violet [Merck]. The injections were made near the junction of the cancer with healthy skin as the solution could not be thrown into its body. The odor immediately disappeared, but in a few days the mass begau to slough and on the day of death the entire mass dropped off leaving the face perfectly clear and free from cancerous tissue. Had the man not died from exbaustion and septic poisoning lie probably would have been cured.

The question naturally arises whether this method of treatment is not, after all, about the same as that of Marsden's paste, the ointment of sorrel, etc., used by "caucer doctors." Instead of being applied externally, it is injected, causing death of the malignant growth without suppuration. simply because it is ased hypodermically. 'The sloughing in Dr. Griffith's last case presents the clinical aspects of cancers treated by means of paste. It is not at all unlikely that pyoktanin has no specific action, and that the same result might be obtained by the injection of a strong infusion of either oxalidea acetosella or numex-acetosa ["horse-sorrel"], or even of binoxalate of potash or oxalic acid.

\section{MISCELLANY.}

MEDICAL SOCIETY OF VIRGINIA. - The twenty-second annual session of the Medical Soeiety of Virginia will convene in the hall of the Young Men's Christian Association, in the city of Lyuchburg, Va., at 8 P. M., Tuesday, October 6th, I89r, and will continue in session through Wednesday, Thursday, and probably a part of Friday.

On entering the hall each Fellow, Honorary Fellow, Fraternal Delegate and Invited Guest should register his name, postoffice, etc., in the book for that purpose, which will be on one of the desks of the Recording Secretary.

Tuesday night's session will be open to the public. It will be called to order at 8 P. M. by the President, Dr. William W. Parker, of Richmond, Va. After prayer, the address of welcome will be delivered by Dr. H. Gray Latham, of Lynchburg, Va.

The address to the public and profession will then be delivered by Dr. Chas. M. Blackford, of I.ynchburg, Va., his subject being "Medical Education as It Was; as It Is; and as It Should Be."

The Committee on Nomitation of Applicants for Fellowship will make their.report, and at once the vote will be taken on the nominations. Each gentleman, as soon as elected, becomes a Fellow, and is entitled to all the privileges and benefits of the Society.

Such other business of a general character as can be disposed of may then be introduced, including motions or resolutions that have to be referred to committees, reports of officers, announcements, etc.

Ex-President and Honorary Fellow, Hunter McGuire, M.D., LL.D., etc., of Richmond, Va., during the last session, authorized the announcement that he would offer a prize of one hundred dollars for the best original essay on pyelo nephrites, presented by a Member or Fellow of either of the State Medical Societies of Virginia, West Virginia or North Carolina, of each of which he is an Honorary Fellow. All essays offered in competition must be considered as under the control of the Medical Society of Virginia or its Committee on Publications. The essay to which the prize is awarded will be published in the transactions of the Medical Society of Virginia and in such regular medical journals as may desire it.

The conditions of the competition are that the competing essays must be in the hands of the Recording Secretary of the Medical Society of Virginia by the first day of September, I89I. They must be type-written or printed. Each one must be designated by a motto on MS. (not by the author's name or other mark by which the identity of the author is made known), and accompanied by a sealed envelope, with the adopted motto on the outside, and a card inside, giving the name and postoffice address of the author. In advance of the session, the several competing essays are to be examined by a committee appointed by the President of the Medical Society of Virginia. This committee will report the two best essays in their hands, each of which is to be read hefore the Society, and the prize will be awarded to the one that a ballot vote may determine to be the best.

It is understood that either the Examining Committee or the Society shall have power to determine whether or not either of the essays possesses sufficient merit to entitle the author to the prize.

The following resolution, introduced last year (see Transactions I 89o, pages 291-295), requires action during this session:

By Dr. George T. Walker, of Vinton:

Resolved, That the President of the Medical Society of Virginia appoint a committee, consisting of three Fellows, to consider the practicability of designating a time during each annual session, for the holding of clinics, and for clinical instruction, and report at the next annual session.

Committee on above: Drs. Geo. T. Walker, A. C. Palmer and Wm. T. Walker.

Practically bearing on the same subject, Dr. J. N. Upshur of Richmond moved (see Transartions I 890 , page 3 II), that a committee of three Fellows be appointed, to report during the session of $I 89 \mathrm{I}$, as to the propriety of recommending that a portion of some day of each anuual session be set apart for the reports of cases, asking advice, etc.

Committee: Dr. J. N. Upshur, of Richmond; Honorary Fellow Dr. J. L. Ashton, of Dallas, Texas, and Dr. Thomas P. Mathews, of Manchester, Va.

During the session of 1890 (see Transactions 1890 , pages 292-295), Dr. Hugh M. Taylor, of Richmond, Va., introduced a resolution to do away with the present system of annually appointing Reporters on Advances in the several departments of medical science, and in lieu thereof select aunually some subjects for full investigation and discussion during the succeeding annual session, appointing several Fellows to report on given subdivisions of the subjects, so that the several reports or papers by different authors, when systematically arranged for publication in the Transactions, will practically form one continuous treatise or monograph on each of the several subjects so selected.

After full discussion, on motion by Dr. J. F. Winn, of Richmond, a committee of five Follows was ordered to appointed to take the whole subject under advisement and report during the annual session of I89I.

The President appointed Drs. J. F. Winn and Hugh M. Taylor, of Richmond; I. S. Stone, of Washington, D. C.; Honorary Fellow Dr. Benjamin Blackford, of Staunton, and Dr. John Grammar, of Halifax C. H.

On Wednesday morning, October 7 th, at ro o'clock, the Society will be called to order. Business of a general character will be in order until is o'clock, when the President, Dr. William W. Parker, of Richmond, will deliver the annual address of the President.

The subject for general discussion, Acute and Chronic Dysentery, will then be called. The subject will be opened by a paper by the leader, Dr. P. B. Green, of Wytheville, Va. Dr. Wm. J. Crittenden, of Unionville, Va., will follow with a paper having the same title. Honorary Fellow Dr. Bedford Brown, of Alexandria, Va., will follow with a paper on "Dysentery Viewed as a Septic Disease, and 'Treated by Antiseptics." After this paper, the discussion will be open to Fellows, Delegates and Invited Guests, in the order of their recognition upon the floor by the chair, the right of closing the discussion being accorded to the leader, Dr. Green.

The afternoon meeting will be consumed in the election of officers, including the nomination to the govern. 